\title{
KONSEP DAKWAH PERDAMAIAN DI ERA KONTEMPORER
}

Oleh:

Andy Dermawan

UIN Sunan Kalijaga Yogyakarta

Email: andy_derma@yahoo.com

\begin{abstract}
Abstrak
Istilah dakwah, senantiasa merujuk kepada seruan kebenaran, panggilan kebaikan, dan ajakan kepada tindakan yang membawa nilai-nilai relijiusitas bagi kepentingan kemanusiaan. Berdakwah tidak cukup menyeru, mengajak dan memanggil kepada kebaikan dan kebenaran, tetapi juga perlu memperhatikan fakta sosial dan budaya yang ada di sekitar. Kajian ini secara keilmuan membagi dakwah menjadi dua wilayah kajian, yakni dakwah normatif dan dakwah historis. Kajian ini menghasilkan temuan, bahwa secara normatif, nash/teks keagamaan perlu didekati secara historis, agar mampu dimengerti maksud dari nash/teks keagamaan tersebut. Dengan demikian, maka kehadiran agama dengan kitab sucinya sesungguhnya lebih dimaksudkan agar manusia lebih termanusiakan dengan menginternalisasikan nilai-nilai agama (Islam) dalam kehidupanya.
\end{abstract}

Kata kunci: dakwah Islam, perdamaian, kemanusiaan.

\begin{abstract}
The term of da'wah, always refers to the call for truth, the call for kindness, and an invitation to the action of religious values to the interest of humanity. Preaching is not merely to invite and to call to the good and truth, but also need to pay attention to the social and cultural facts that are around.This study scientifically divides da'wah into two study areas, namely normative preaching and historical preaching. The findings showed that normatively, religious texts /nash need to be approached historically to obtain their meaning. Thus, the presence of religion with its holy book is actually intended to humanize humanity by internalizing the values of religion (Islam) in their live

Keywords : preaching of islam, peace, humanity

\section{PENDAHULUAN}

Bukan persoalan mudah (da`i) menjelaskan maksud kitab suci kepada orang lain (mad`u). Dibutuhkan kepiawaian di dalam menjelaskan, serta dibutuhkan kecerdasan di dalam memahaminya. Itulah jalan dakwah. Sesungguhnya tugas dakwah yang diemban oleh setiap individu muslim di

dalam kehidupan sehari-hari disadari atau tidak, seringkali di setiap ajakan, seruan dan panggilan kepada kebaikan dan kebenaran itu "terselip" kepentingan individu yang mengubah tujuan dakwah sesungguhnya. Tumpang tindihnya (over laping) antara kebenaran yang harus diseru dan kepentingan yang menumpang dalam seruan itu akhirnya menjadi suatu
\end{abstract}


ambivalensi yang sulit diurai. Maka akibatnya bisa ditebak, dakwah berujung masalah.

Al-Qur`an mengajarkan dalam surat ke 36 ayat 58, "Damai, demikianlah sapaan dari Tuhanmu Yang Maha Penyayang kepada mereka yang cinta damai”, dan al-Qur`an surat ke-7 ayat 199, "Berikanlah pengampunan, bimbinglah kearah kesepakatan (damai) dan jangan bodoh (melawan kekerasan dengan kekerasan)". Dua kalimat tersebut merupakan terjemah "bebas" dari ayat al-Qur'an yang penulis kutip redaksionalnya dari halaman pembuka buku karya Zakiyuddin Baidhawy berjudul Ambivalensi agama, Konflik dan Nirkekerasan (2002), dan dieditori oleh Andy Dermawan. Menunjukkan, bahwa kitab suci al-Qur`an pun menganjurkan berlaku cerdas di dalam menyampaikan pesan-pesan Islam kepada masyarakat. Cara menyampaikan secara baik dan komunikatif, tanpa harus menyampuradukkan antara Islam dan budaya, serta mengkonfrontasikan antara nilai-nilai Islam dan dinamika kehidupan manusia sehari-hari, akan mampu memberikan informasi yang baik dan benar tentang Islam kepada khalayak umum. Jalan dakwah mengenal proses, dan proses itu memberikan cukup waktu untuk memahami maksud kitab suci yang baik itu.

Tulisan ini berikhtar mengkaji tentang dinamika dakwah yang terefleksikan secara keilmuan menjadi dua wilayah, yakni dakwah normatif dan dakwah historis. Kajian ini berusaha merumuskan suatu pandangan tentang dakwah perdamaian, bahwa nilai-nilai religiusitas Islam itu akan terejawentah baik apabila cara memahaminya secara konprehensif dan integratif. Berdasarkan pandangan ini diharapkan, bahwa dakwah perdamaian itu dapat tercapai manakala wilayah dakwah normatif yang berdasarkan teks/nash suci itu dipahami secara historis, berdasarkan dinamika yang dihadapi manusia dewasa ini.

\section{PEMBAHASAN}

\section{Pengertian Dakwah}

Terminologi “dakwah” berasal dari bahasa Arab, yakni da`a, yad`u, da`watan yang mempunyai pengertian memanggil, menyeru, mengundang atau mengajak (Hafiz Dasuki: 1994; Abdul Mun`im Hanafi, t.t.). Memanggil untuk besujud kepada Allah, menyeru kepada kebajikan, mengundang kepada kebenaran, dan mengajak seluruh umat manusia arah kebaikan menuju Tuhan secara bersama-sama dengan cara 
bijaksana untuk mencapai kemaslahatan dan kebahagiaan di dunia dan akhirat.

Menurut Bakhial Khauli sebagaimana dikutip oleh Munzier Suparta dkk. Dalam buku Metode Dakwah, menyatakan bahwa dakwah adalah satu proses menghidupkan peraturan-peraturan Islam dengan maksud memindahkan umat dari satu keadaan kepada keadaan lain. Lebih dari itu, dakwah juga mengajak manusia untuk mengerjakan kebajikan dan mengikuti petunjuk-Nya. Pendek kata, amar ma`ruf nahi munkar adalah inti gerakan dakwah dan penggerak dinamika masyarakat Islam (Munzier Suparta dkk.: 2003). Tegasnya, dakwah merupakan proses transformasi dinamik nilai-nilai Islam yang bertujuan agar manusia memperoleh suatu pencerahan (enlightenment) di dalam cara berpikir, sikap mental dan perilaku berdasarkan ajaran agama Islam. Pencerahan yang dimaksudkan adalah adanya perubahan cara berpikir yang menegaskan bahwa penyembahan merupakan kunci semua aksi. Apa yang disembah menentukan apa yang dilakukan. Jika seseorang menyembah singa ia akan mengaum, dan jika ia menyembah berhala maka ia akan membatu. Itulah substansi aqidah (tauhid) seorang muslim di dalam mengabdi kepada Allah Swt.

Perubahan selanjutnya pada sikap mental seseorang yang terimplikasi dari prinsip-prinsip ketauhidannya yang dipegang teguh selama ini di dalam menjalani kehidupannya sehari-hari, seperti bertindak tegas terhadap segala bentuk kemaksiatan, santun kepada orang tua dan guru, menjaga kejujuran, membangun kebersamaan, dan bahkan terbuka serta mengakui dengan rendah hati bahwa ada kebenaran di luar dirinya.

Sedangkan pada perilaku, mampu melahirkan akhlak yang mulia, di mana orang lain tidak terganggu oleh ulah mulut dan tangannya. Pendek kata, seorang yang mengalami pencerahan adalah orang yang mampu berpikir pada dataran makna dan bertindak cerdas di dalam mengambil keputusan tindakan di dalam hidupnya.

Pada hakikatnya, setiap individu muslim adalah marketing Tuhan, seorang muslim berkewajiban menyampaikan kebenaran ajaran Islam melalui dakwah dengan cara-cara yang santun, bijaksana, tegas, bahasa yang dapat dipahami oleh semua orang (mad'u) (Andy Dermawan: 2007), dan bahkan tanpa harus mencaci maki Tuhan orang-orang kafir yang dikhawatirkan nantinya akan 
menyebabkan ia memaki Allah swt (al-Qur`an, ayat ke-6, 108).

\section{Dakwah : Pertautan Visi dan Aksi dalam Tradisi Keilmuan}

Secara keilmuan, penulis membagi dua hal wilayah keilmuan dakwah, yakni dakwah normatif dan dakwah historis. Selanjutnya lihat bagan di bawah ini.

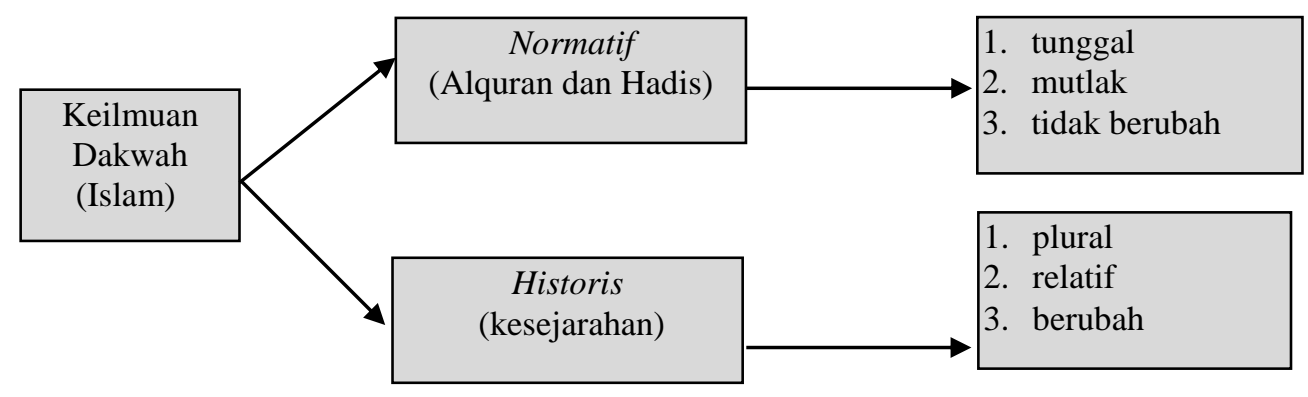

Istilah dakwah normatif dan dakwah historis ini merupakan tawaran metodologis penulis yang dipakai di dalam memahami problematika dakwah (Andy Dermawan: 2002). Adapun penjelasan keduanya sebagai berikut. Pertama, Dakwah Normatif, yakni dakwah yang bersumber asli dari alQur`an dan Hadis Nabi Muhammad Saw. yang dikaji secara sistematik-dialektishermeneutik agar ajaran atau nilai-nilai intinya dapat ditangkap secara utuh tanpa melakukan reduksi atas keduanya, dan karakteristik dari dakwah normatif ini adalah "taken for granted", tetap dan tidak berubah-ubah, dan kedua Dakwah Historis, yakni dakwah yang berkembang pasca Nabi Muhammad Saw. wafat sampai dengan sekarang ini yang dijadikan pertimbangan untuk memahami kedua sumber tersebut (Alquran dan Hadis). Sedangkan karakteristik dari dakwah historis ini adalah selalu terbuka untuk menerima perubahan, kritik, di samping dipakai juga untuk memberikan pemaknaan dan pemahaman kembali terhadap realitas dakwah yang ada. Inilah dakwah sebagai proses.

Secara implementatif, penjelasan dakwah historis dipakai untuk memahami dakwah normatif yang bersifat tetap dan tidak berubah-ubah. Adapun dakwah historis senantiasa mengalami perubahan di dalam memahami dan memaknai kembali dakwah dan segala problematikanya. Jadi, bukan nash/ teks sucinya yang diubah, tetapi pemahaman 
manusia terhadap nash/ teks itulah yang harus selalu mengalami pembaharuan atau pencerahan di dalam memaknai nash/ teks tersebut sesuai dengan dinamika zaman. Inilah sesungguhnya bentuk dinamik pertautan antara visi dan aksi, yakni dakwah normatif dan dakwah historis.

Setelah memahami dakwah normatif dan dakwah historis, maka langkah yang dilakukan berikutnya adalah mengintegrasikan keduanya dalam ranah tehnis, yakni antara dakwah normatif dan dakwah historis berhubungan secara fungsional. Melalui cara ini, maka pengejawentahan nlai-nilai Islam dapat dimengerti secara konprehensif dan utuh.

\section{Dakwah Normatif : \\ Dasar Membangun Visi Kemanusiaan}

Buku berjudul Tauhid Sosial menjelaskan, bahwa Tauhidullah sesungguhnya menurunkan atau mengisyaratkan adanya lima paket pengertian (Amien Rais: 1998, 109). Pertama, tauhidullah jelas mengajarkan kepada kita bahwa harus yakin, beriman, tentang adanya Unity of Godhead, yaitu kesatuan ketuhanan. Kedua, kesatuan ketuhanan ini pada konsekuensi logis berikutnya menimbulkan Unity of
Creation, kesatuan penciptaan. Seluruh makhluk di alam semesta ini, baik yang kasatmata maupun yang tidak kelihatan, baik yang bisa dideteksi, diobservasi, diukur dengan alat-alat pengukur maupun di luar itu, yang gaib maupun yang lahir, dalam konsep tauhid semua merupakan ciptaan Allah. Ketiga, konsekuensi berikutnya, karena umat manusia merupakan bagian dari makhluk Allah, maka tentu kita harus percaya akan adanya Unity of Mankind, kesatuan kemanusiaan. Jadi, semboyan Mankind is One, terlepas dari warna kulit, latar belakang, bahasa, geografi, sejarah, dan segala macam perbedaan yang melatarbelakangi keragaman umat manusia, tidak menghilangkan pengertian substantif atau sangat prinsipil bahwa di dunia ini ada kesatuan kemanusiaan. Keempat, karena ada kesatuan kemanusiaan, tentu ada Unity of Guidance, kesatuan pedoman hidup bagi orang yang beriman. Pedoman hidup itu adalah wahyu Allah Swt. Jadi, karena manusia ciptaan Allah, maka hanya Allah yang merupakan Zat yang paling mengetahui ke mana manusia harus pergi, usaha apa yang harus dilakukan umat manusia agar tercapai kebahagiaan di dunia dan akhirat. Kelima, karena adanya Unity of Guidance, maka 
akhirnya hidup kita di alam fana ini akan bermuara kepada khir yang sama. Sehingga, tujuan hidup umat manusia seharusnya sama secara konseptual dan teoritis, yaitu adanya Unity of the Purpose of Life, adanya satu kesatuan tujuan hidup (Bandingkan dengan Ali Yafie: 1997).

Orientasi tauhid sosial dengan kelima prinsip tersebut sesungguhnya mengarah kepada keadilan sosial yang bermartabat. Suatu keadilan yang lebih menuntut kepada keridlaan Allah semata daripada menuntut berlebih soal ganjaran dan sorga-Nya, meskipun itu wajar adanya.

Bagi penulis, tauhid pada hakikatnya tidak sekadar mengesakan Allah dan tidak membaginya dengan yang lain, tetapi juga berimplikasi kepada kehidupan riil manusia sehari-hari di dalam segala aktifitasnya. Sejak dari cara berpikir, sikap mental, sampai dengan perilaku merupakan cerminan utuh dari visi tauhid.

Berdasarkan cara pandang sebagaimana dijelaskan di atas, maka dakwah semestinya menjadi media transformasi emansipatoris. Maksudnya, bahwa dakwah harus mampu membantu masyarakat untuk mencapai otonomi dan kedewasaan berpikir dan cerdas dalam bertindak. Karena hakikat ketauhidan seseorang itu adalah satunya pikiran dan tindakan. Masyarakat yang cerdas adalah yang berhasil melakukan komunikasi yang baik dan saling memahami dengan sesama dalam interaksinya. Dalam konteks ini, dakwah perlu diubah pemahamannya, yakni pemahaman transformasi nilai dari dogma individu menuju kesadaran kolektif. Dogma individu yang selama ini terjadi adalah menganggap final doktrin agama tanpa mengkaji ulang apa yang sesungguhnya menjadi perintah dan larangan dalam ajaran agama Islam itu sendiri atau "apa yang sesungguhnya maksud dibalik teks/nash itu" (ma wara al-musykilat). Sehingga terjadi benturan pemahaman dan berakhir kepada sikap apriori, taken for granted, dan bahkan menganggap salah pemahaman orang lain. Di sinilah pentingnya dakwah mengikuti perkembangan manusia secara terusmenerus.

Penting untuk diketahui, bahwa masyarakat (muslim) dewasa ini bukanlah masyarakat yang bodoh, dan tidak tahu apa-apa, tetapi mereka memiliki wawasan yang relatif sama dengan lainnya. Sudut pandanglah (perspective) yang membedakan satu sama lainnya. Oleh karena itu, yang 
penting adalah ada kesetaraan antara dirinya (da`i) dan yang didakwahi (mad $u$ ) di dalam memahami secara bersama-sama ajaran agama Islam sebagai fundamental structure seseorang di dalam menjalani kehidupan. Selanjutnya, yang menjadi tolok ukur normatifnya, adalah menjadikan nilainilai ajaran Islam sebagai sumber kebenaran di dalam mengambil keputusan tindakan, dan tolok ukur historisnya adalah menjadikan sumber ajaran tersebut dipahami dan dimaknai ulang sesuai dengan kondisi jaman. Jadi, bukan teks/ nash sucinya yang diubah melainkan pemahaman manusia terhadap teks/ nash itu sendiri yang perlu diperbaharui.

Kondisi riil kehidupan manusia dewasa ini menunjukkan, bahwa telah terjadi pemisahan antara dimensi ilmu dan nilai-nilai realitas hidup yang kompleks. Seolah ilmu berbicara pada dataran konsep dan nilai-nilai realitas kehidupan pada dataran riil. Ilmu dipahami sebagai ilmu (ilmu untuk ilmu), sedangkan nilai-nilai realitas dipahami sebagai nilai yang terlepas dari teks dan konteksnya. Inilah yang disebut Geuss dengan false consciousness, yakni sebuah kesadaran palsu yang merintangi hubungan antara ilmu dan pengetahuan dalam realitas social (R. Geuss: 1981, 12). Contohnya, ketika nilai-nilai Islam dianggap sudah tidak relevan lagi dengan kebutuhan jaman, dan dianggap terlalu mencampuri dan merintangi aktivitas kehidupan manusia. Padahal, yang benar adalah justru nilai-nilai relijiusitas Islam itu memberikan batas atau garis demarkasi yang tegas antara haq dan bathil, salah dan benar, baik dan buruk. Kembali kepada persoalan utama, di sinilah urgensinya dakwah tranformatif, yakni membangun kesadaran masyarakat agar mampu memahami dan menerima bahwa nilai-nilai Islam yang disampaikan melalui dakwah dapat memberikan pencerahan bagi manusia.

Pada dasarnya dakwah mempunyai peran baik untuk melontarkan gagasan transfromasi nilai dalam memaknai setiap perilaku manusia. Hakikat dakwah pada dataran inilah, diharapkan para pembawa "kabar dari langit" itu mampu mengarifi problematika dakwah di dalam mentransformasikan nilai, sehingga "dimensi langit suci" lebih dapat dibumikan untuk dipahami oleh manusia secara sadar dan bertahap.

Beberapa hal yang penting diperhatikan di dalam membangun visi kemanusiaan menuju dakwah perdamaian. Pertama, membangun 
sensitifitas kemanusiaan dan tidak berorientasi pada radikal-konfrontatif. Sensitifitas kemanusiaan dimaksudkan adalah membangun rasa kebersamaan di dalam menuju kebaikan bersama sebagai umat manusia. Terlepas dari perbedaan suku, ras dan agama, setiap individu diikat oleh kemanusiaannya. Kedua, membangun gerakan partisipatoris di dalam menegakkan rasa keadilan dan kebenaran dalam masyarakat. Wilayah ini kuat dengan berkembangnya keterbukaan, egaliter, dan sikap humanis antar sesama. Ketiga, membangun kesadaran bersama, bahwa tingginya kualitas kemanusiaan itu di atas segalanya, untuk diperjuangkan secara terus-menerus.

\section{Islam dan Keragaman}

Bukan persoalan mudah memaknai pluralitas. Bukan masalah sederhana pula mengerti maksud Tuhan sebagaimana terkandung dalam kitab suci-Nya. Terlebih berkaitan dengan agama yang notabene memiliki sensitifitas tersendiri bagi pemeluknya. Meski diakui, bahwa dalam kehidupan umat manusia di dunia, pasti selalu ditemukan adanya pluralitas atau keragaman. Pluralitas yang menyangkut kehidupan manusia, seperti warna kulit, bahasa, dan adat istiadat memiliki dimensi keragaman sebagaimana koin mata uang, antara sisi satu dan lainnya berbeda, tetapi tak bisa dipisahkan atau bahkan disamakan. Alquran surat Ar-Ruum ayat 22 menegaskan,

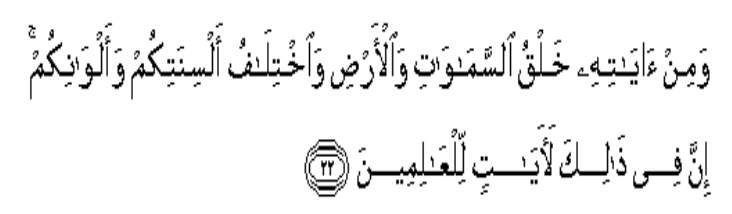

Artinya: Dan di antara tanda-tanda kekuasaan-Nya ialah menciptakan langit dan bumi dan berlain-lainan bahasamu dan warna kulitmu. Sesungguhnya pada yang demikan itu benar-benar terdapat tanda-tanda bagi orang-orang yang mengetahui.

Musa Asy`arie berpendapat, bahwa dalam setiap realitas yang plural itu, tidak ada yang persis sama, baik ukuran warna, rupa maupun dimensinya. Sehingga, masing-masing realitas parsial itu satu sama lain berbeda-beda. Anak yang lahir dari ibu dan ayah yang sama, mekipun mereka anak kembar sekalipun, tidak berarti sama persis dalam berbagai aspek kehidupannya, baik bentuk tubuh, perasaan dan pikirannya maupun realitas eksistensialnya kehidupan sosial, ekonomi, politik, budaya dan sebagainya. Adanya pluralitas dalam kehidupan masyarakat sesungguhnya membuat kehidupan masyarakat itu dinamis, penuh warna, tidak membosankan, dan 
membuat antara yanga satu dengan yang lainnya saling melengkapi dan membutuhkan. Dengan kata lain, pluralitas memperkaya kehidupan dan menjadi esensi kehidupan masyarakat sehingga tindakan untuk menolak ataupun menghilangkan adanya pluralitas, pada hakikatnya menolak esensi kehidupan. Sungguh pun demikian, kita juga tidak dapat menutup mata pada adanya kenyataan bahwa dalam kehidupan masyarakat yang plural, tetapi di dalamnya berlangsung ketidakadilan, kemiskinan, kebodohan dan lemahnya hukum serta rendahnya disiplin masyarakat. Kalau itu yang terjadi, pluralitas dapat berubah menjadi ancaman yang seringkali memicu timbulnya ketegangan, pertentangan, bahkan konflik yang seringkali mengambil bentuk kekerasan (Musa Asy`arie: 2002).

Buku Islam dan Multikulturalisme di Indonesia: Ikhtiar Mengurai Akar Konflik menjelaskan bahwa pada hakikatnya manusia berpotensi untuk berbenturan sekaligus bersinergi. Potensi berbenturan, oleh karena manusia memiliki suatu spirit untuk berkompetisi dengan manusia lain dalam segala hal (fastabiq al-khairat, berlomba-lomba dalam kebaikan).
Potensi bersinergi, oleh karena manusia tidak mampu hidup sendirian dalam alam jagad raya ini. Hidupnya bergantung pada yang lain, yakni bergantung kepada sesama, tumbuh-tumbuhan dan hewan untuk diambil manfaat dan dikelola potensi sumber dayanya. Jika potensi berbenturan itu diperlebar jaraknya, maka yang terjadi adalah suatu kompetisi brutal yang cenderung menghalalkan segala cara. Tetapi jika potensi sinergi yang dioptimalkan, maka kompetisi yang dilakukan sesuai dengan kompetensi yang dimiliki oleh setiap individu. Bukan berdasarkan kalah-menang, melainkan pada penguatan kompetensi masingmasing individu dalam kebersamaan. Ada tanggungjawab, kerjasama dan masing-masing unggul berdasarkan kompetensinya (Andy Dermawan: 2009).

Potret masyarakat Indonesia merupakan kumpulan dari seribu wajah dan pikiran yang masing-masingnya membentuk keragaman etnik, suku, ras dan bahkan keyakinan. Pola berpikir dan berbudaya suatu etnik merupakan entitas masyarakat yang memiliki world view (pandangan dunia) dan cenderung berbeda dengan yang lain. Kecenderungan itu bukanlah suatu hal yang salah dan mengada-ada. Sebab kecenderungan berbeda merupakan 
rangkaian nilai-nilai yang membentuk kultur dan kepribadian suatu kelompok masyarakat tertentu. Perbedaan itu suatu keniscayaan, oleh karena pengaruh cara pandang dan sudut pandang terhadap permasalahan. Jika demikian realitanya, maka yang perlu dibangun adalah sikap kita terhadap pola pikir dan pola budaya masyarakat tertentu, agar kita mampu bersinergi dari segala perbedaan yang ada. Bersinergi adalah menyediakan diri untuk mampu hidup bersama dalam setiap perbedaan di masyarakat. Bersinergi juga merupakan mencari titik temu dari perbedaan-perbedaan yang terjadi.

Berdasarkan pemaparan tersebut di atas, menegaskan bahwa Islam mengakui pluralitas. Pluralitas dalam kajian Islam merupakan suatu keniscayaan dalam kehidupan manusia. Dengan mengakui bahwa perbedaan di antara manusia adalah rahmat, maka secara tidak langsung, akar-akar konflik telah diminimalisir sedini mungkin, setidaknya mulai dari cara berpikirnya.

\section{KESIMPULAN}

Setiap manusia muslim adalah marketing Tuhan. Wujud konkret dakwah bukanlah sekadar usaha peningkatan pemahaman keagamaan dalam pandangan hidup dan berperilaku saja, melainkan juga mengubah cara berpikir, sikap mental dan perilaku di dalam memahami dinamika sosial dan budaya yang ada. Semua itu digunakan untuk melihat dan menelaah realitas plural, karena keragaman itu adalah karya Tuhan. Berikutnya, diperlukan pemahaman ajaran Islam secara utuh dan konprehensif, karena semua persoalan yang terjadi hanya mampu dipahami secara multidimensional. Dengan demikian, dapat digarisbawahi bahwa konsep dakwah perdamaian adalah dakwah yang menjunjung tinggi visi kemanusiaan berdasarkan al-Qur`an dan Hadis, serta mengakui bahwa pluralitas itu merupakan suatu hal yang niscaya. 


\section{DAFTAR PUSTAKA}

Abdul Mun`im Hanafi. t.t. Al-Mu`jam al-Falsafi. Mesir: Dar al-Syarkiyah.

Ali Yafie. 1997. Fiqih Sosial, Bandung: Mizan.

Andy Dermawan. 2009. Islam dan Multikulturalisme: Ikhtiar mengurai Akar Konflik, Yogyakarta: PT. Tiara Wacana.

Andy Dermawan. 2007. Ibda`Binafsika, Yogyakarta: PT. Tiara Wacana. Edisi ke-2.

2002. "Strategi Dakwah

Islam dalam Pendekatan Rasional Transendental", dalam Jurnal alJamiah, Universitas Islam Negeri Sunan Kalijaga, Juni, 2002.

Dakwah, Yogyakarta: Lesfi. 2002. Metodologi Ilmu

Departemen Agama RI. 1995. Al-Qur`an dan Terjemahnya, Jakarta: PT. Intermasa.
Geuss, R. 1981. The Idea of Critical Theory, Cambridge: Cambridge University.

Hafiz Dasuki. 1994. Ensiklopedi Islam, PT. Ichtiar Baru van Hoeve: Jakarta.

Jurgen Habermas. 1971. Knowledge and Human Interests, transl. by Jeremy J. Shapiro, Boston: Beacon Press.

Munzier Suparta dkk. 2003. Metode Dakwah, Jakarta: Rahma Semesta.

Muhammad Amien Rais. 1998. Tauhid Sosial: Formula Menggempur Kesenjangan, Bandung: Mizan..

Musa Asy`arie. 2002. Dialektika Agama untuk Pembebasan Spiritual, Yogyakarta: Lesfi.

Zakiyuddin Baidhawy. 2002. Ambivalensi Agama, Konflik dan Nirkekerasan, Yogyakarta: Lesfi. 